\title{
Emergency Linkage Mode of Power Enterprise
}

\author{
FENG Jie ${ }^{1, a}$, YU Zhen ${ }^{1}$ and LIU Chao ${ }^{1}$ \\ ${ }^{1}$ State Grid Smart Grid Research Institute, Information \&communication research department, Beijing, China
}

\begin{abstract}
Power emergency disposal needs take full advantage of the power enterprise within the external emergency power and resources. Based on analyzing and summarizing the relevant experience of domestic and foreign emergency linkage, this paper draws the Emergency Linkage subjects, Emergency Linkage contents, Emergency Linkage level, which are three key elements if power enterprise Emergency Linkage. Emergency Linkage subjects are divided into the two types of inner subjects and the external body; Emergency Linkage contents are in accordance with four phases of prevention, preparedness, response and recovery; Emergency Linkage level is divided into three levels of enterprise headquarter, provincial enterprise and incident unite. Binding power enterprise emergency management practice, this paper studies the internal Emergency Linkage modes (including horizontal mode and vertical mode), external Emergency Linkage mode and comprehensive Emergency Linkage Mode of power enterprise based on Fishbone Diagram and Process Management Technology.
\end{abstract}

\section{Introduction}

To meet massive power demand caused by the rapid development of national economy, power system has entered the era of ultra-high voltage and interconnected large power system. The safety and stabilization of power system has become an issue that is of great concern to the public. Related research found that power system emergencies feature complicated links, many disaster sources, huge losses and widely affecting [1]. Therefore, it is unable that to deal with the complicated emergencies only relies on the emergency capacity of electricity power.

In modern emergency management, full use of various resources for emergency response has become a trend. Currently, there is less study on the Emergency Linkage of power enterprise. Using the experiences abroad and inside for reference, this paper studies the elements and mode of Emergency Linkage.

\section{The Current Analysis of Emergency Linkage Experiences Abroad and Inside}

\subsection{Foreign Emergency Linkage Experiences}

\footnotetext{
${ }^{a}$ Corresponding author: fengjie_leo@163.com 
Through studying the Emergency Linkage experiences of the United States, Japan, Britain, Australia, it is found the following characteristics

(1). In the United States, the main content of Emergency Linkage is that the relevant emergency departments signed a cooperation contract [2];

(2). In Japan, the main content of Emergency Linkage is that government, companies and nonprofit organizations played a relevant role in emergency response [3];

(3). In the UK, it is an effective solution to the division of responsibilities by established a "gold, silver, copper," three emergency command mechanism [4];

(4). In Australia, the multi-level emergency response mode provided material and financial for emergency disposal [5].

\subsection{Domestic Emergency Linkage Experiences}

In China, civil aviation, subway and other industries explored a lot of useful methods in the Emergency Linkage [6,7], such as, the establishment of emergency response mechanisms in line with industry characteristics; the effective integration of internal and external emergency resources; forming corresponding Emergency Linkage processes, methods and technology; explicit emergency response content and approach; combined the Emergency Linkage and emergency management processes.

\subsection{Summaries of Emergency Linkage Experiences}

Through comprehensive analysis of domestic and foreign Emergency Linkage experiences, we find the following results:

(1) Multiple-subjects Emergency Mechanisms: In emergency management, all kinds the subjects participate in emergency response, mobilized the capacities of each subject get and played their strengths and initiative.

(2) Clear Emergency Linkage Contents: It is clearly defined that procedures and methods of Emergency Linkage, solidified emergency response content, and consolidation Emergency Linkage process;

(3) Scientific Emergency Linkage Grade: For utilizing a limited resource, Emergency Linkage level match to the emergency level.

\section{Emergency Linkage Elements of Power Enterprise}

By analysing the domestic and foreign Emergency Linkage experiences, the study found that Emergency Linkage has three important elements: Emergency Linkage Subjects; Emergency Linkage Content; Emergency Linkage Level. Based on power enterprise practice, three elements of Emergency Linkage are studied.

\subsection{Emergency Linkage Subjects}

A lot of Emergency Linkage Subjects involved in responding to emergencies. In order to make emergency response in an orderly manner, Emergency Linkage Subjects are divided into the enterprise interior subjects and the external subjects. The external subjects include related internal departments of power enterprise, and the external subjects are divided into government departments, rescue organizations, monitoring departments, news media, and power consumers in accordance with their function. The classification is shown in Figure 1. 


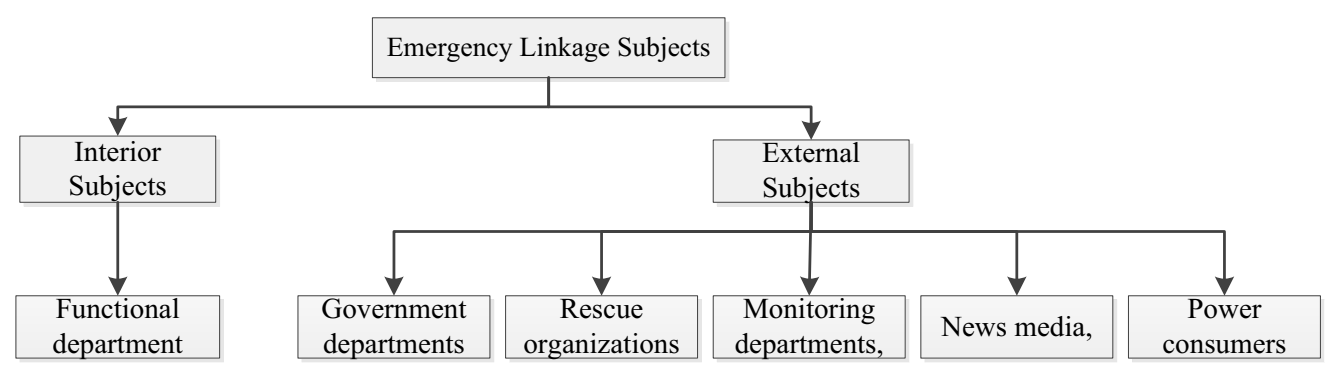

Figure 1. Classification of Emergency Linkage Subjects Emergency Linkage Content

According PPRR theory, emergency management includes prevention, preparation, response and recovery stages [8]. Emergency Linkage Content as an important basis of emergency response work should run through four phases of emergency management. The content involving emergency management four stages is shown in Table 1 .

Table 1. Emergency Linkage Related Content

\begin{tabular}{|c|c|c|c|}
\hline Phase & Content & Phase & Content \\
\hline prevention & $\begin{array}{l}\text { (1)Hazard Management } \\
\text { (2)Monitoring and Control } \\
\text { (3)Public Education }\end{array}$ & response & $\begin{array}{l}\text { (1)Event Information Sharing } \\
\text { (2)Coordination Disposal } \\
\text { (3)Tracking and Monitoring } \\
\text { (4)Public Opinion Management } \\
\text { (5)Resource Allocation } \\
\text { (6)Medical Care }\end{array}$ \\
\hline preparation & $\begin{array}{l}\text { (1)Emergency Linkage Plan } \\
\text { (2)Forecasting and early warning } \\
\text { (3)Emergency Training } \\
\text { (4)Emergency response drills } \\
\text { (5)Emergency Supplies Sharing } \\
\text { (6)Emergency Response agreements }\end{array}$ & recovery & $\begin{array}{l}\text { (1)Recovery Planning } \\
\text { (2)Plan Execution } \\
\text { (3)Disposal of Property Damage } \\
\text { (4)Incident investigation } \\
\text { (5)Summary and Assessment }\end{array}$ \\
\hline
\end{tabular}

\subsection{Emergency Linkage Level}

Power enterprise emergency management is generally divided into three levels: the first level is the enterprise headquarters level; the second level is the provincial enterprises level; the third level is the incident unit level. Each level contains a number of functional departments. In lateral dimension, various functional departments are directed by the emergency leading group. In vertical dimension, lower functional departments are guided by related higher departments. The specific situation is shown in Figure 2

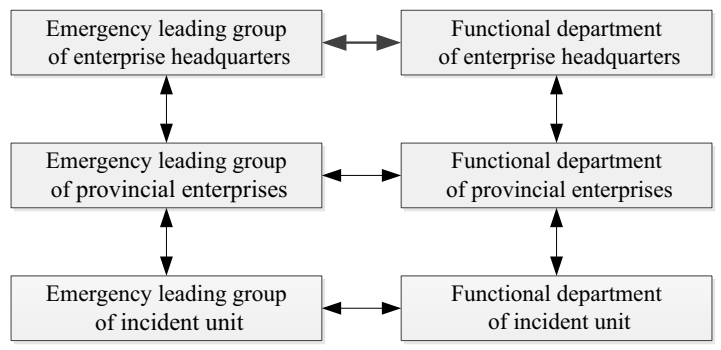

Figure 2. Power Enterprise Emergency Management Organization Relations

Emergency response is a dynamic process. Based on different levels of emergencies, Emergency Linkage Level should be adjusted. When unexpected events affect a large range, it should be taken to a higher Emergency Linkage Level, in order to guarantee the strength and resources of relevant emergency deployment, but also appropriate communication and coordination with external 
emergency rescue departments. When unexpected events affect a lesser range, it should be taken to a lower Emergency Linkage Level. Specific classification method is shown in Table 2.

Table 2. Classification of Emergency Linkage Level

\begin{tabular}{|l|l|l|}
\hline $\begin{array}{c}\text { Emergency Linkage } \\
\text { Level }\end{array}$ & \multicolumn{1}{|c|}{ Emergency Disposal } & \multicolumn{1}{c|}{ Coordination channels } \\
\hline The first level & Over greater emergencies & $\begin{array}{l}\text { The emergency leading group of corporate } \\
\text { headquarters or its authorized units are } \\
\text { responsible for command and coordination. }\end{array}$ \\
\hline The second level & Generic emergencies & $\begin{array}{l}\text { The emergency leading group of provincial } \\
\text { enterprises is responsible for directing and } \\
\text { coordinating. }\end{array}$ \\
\hline The third level & Under generic emergencies & $\begin{array}{l}\text { The emergency leading group of the incident } \\
\text { unit is responsible for directing and } \\
\text { coordinating. }\end{array}$ \\
\hline
\end{tabular}

\section{Emergency Linkage Modes of Power Enterprise}

\subsection{Power Enterprise Internal Emergency Linkage Mode}

\subsubsection{Emergency Linkage Mode of Functional Department}

Corporate functions around the emergency team, comprehensive support, media disposition, recovery and reconstruction of the four emergency response capabilities [9] establish Internal Emergency Linkage mechanism. This study uses the four emergency response capacities as a starting point to analyse the relevant functional departments involved Internal Emergency Linkage and defines mode of Emergency Linkage mode of functional department by Fishbone Diagram. Emergency Linkage Mode of Functional Department is shown in Figure 3.

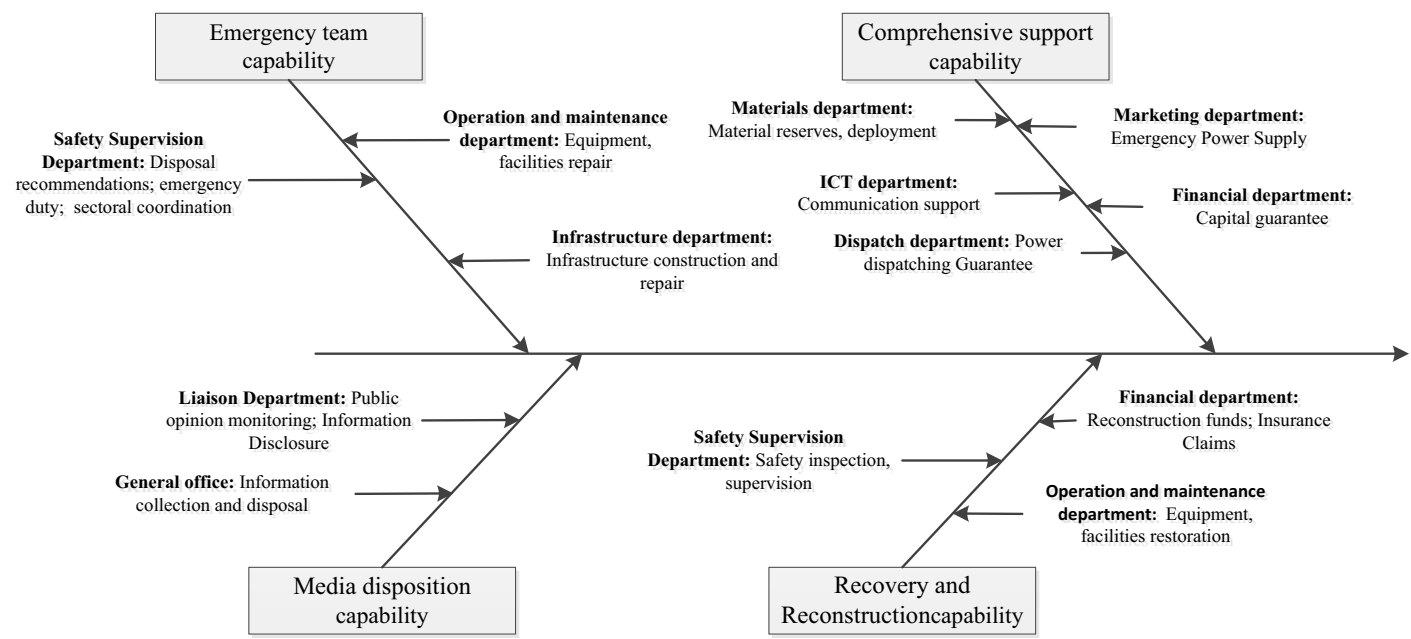

Figure 3. Emergency Linkage Mode of Power Enterprise Functional Department

\subsubsection{Emergency Linkage Mode of Interior Units}

Emergency Linkage of power enterprise interior units covers prevention, preparedness, response, recovery of the four emergency management links. This study designs the mode between the incident unit and linkage units by Process Management Technology. The mode is shown in Figure 4. 


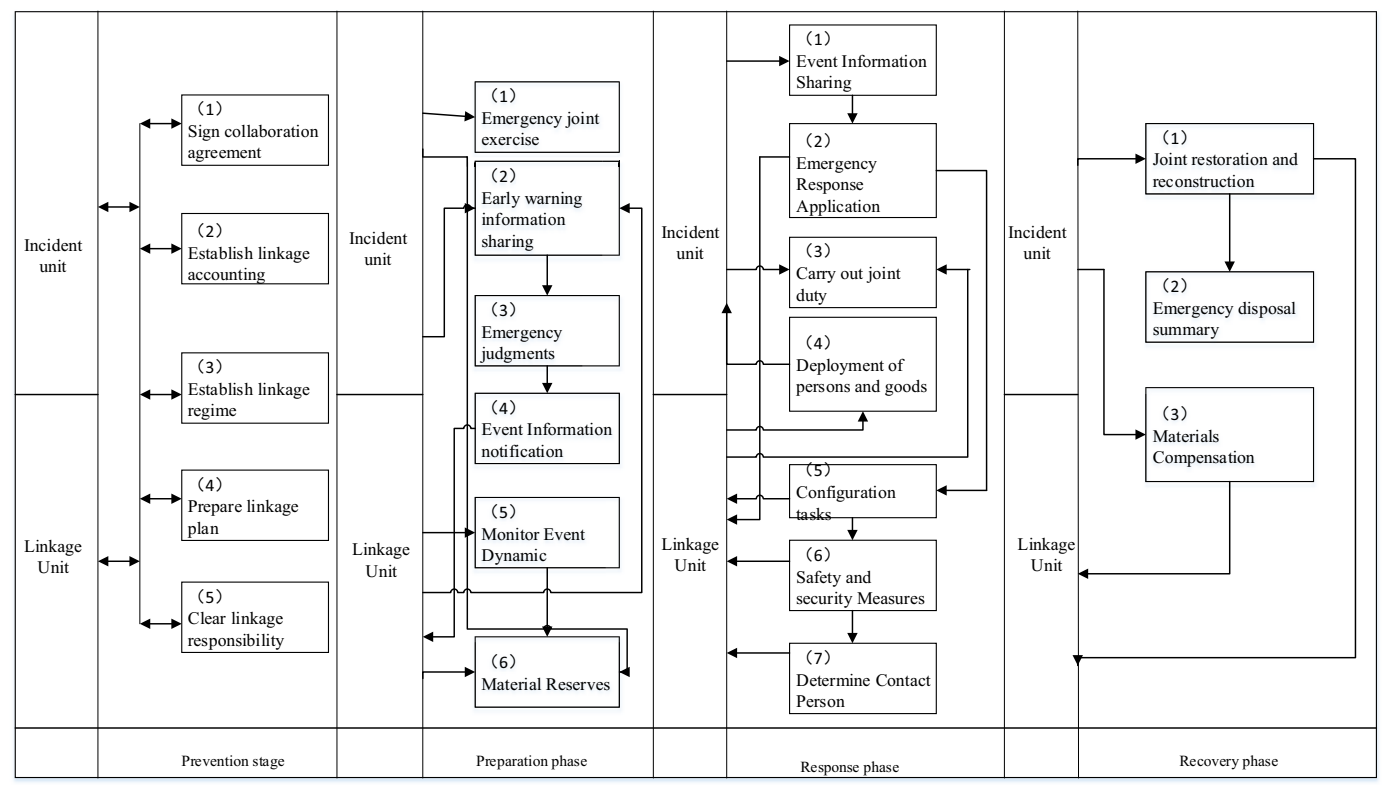

Figure 4. Emergency Linkage Mode of Power Enterprise Interior Units

\subsection{External Emergency Linkage Mode}

In the external Emergency Linkage, Power Enterprise needs to build connection with relevant external subjects, such as rescue agency, monitoring authorities, news media, power consumers, etc., in order to ensure that the whole process of emergency management emergencies. External Emergency Linkage activities also cover the four links of emergency management. This study designs external Emergency Linkage mode by Process Management Technology. The mode is shown in Figure 5.

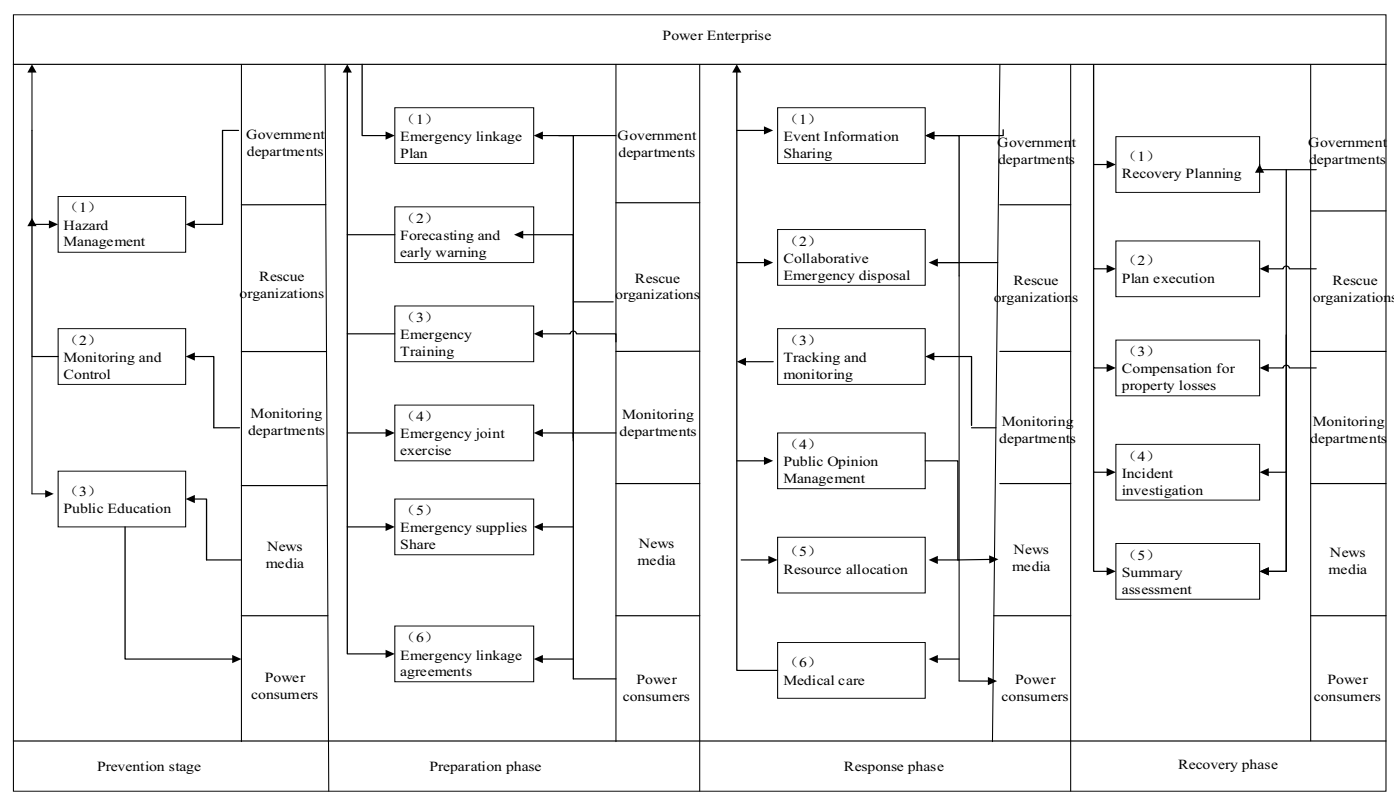

Figure 5. External Emergency Linkage Mode 


\subsection{Comprehensive Emergency Linkage Mode}

In emergency management, it is necessary to build linkage mechanism between power enterprise and external departments. Based on the study of power enterprises Emergency Linkage elements, it is designed that comprehensive Emergency Linkage mode by integrating power enterprise Internal Emergency Linkage mode and external Emergency Linkage Mode. The mode is shown in Figure 6.

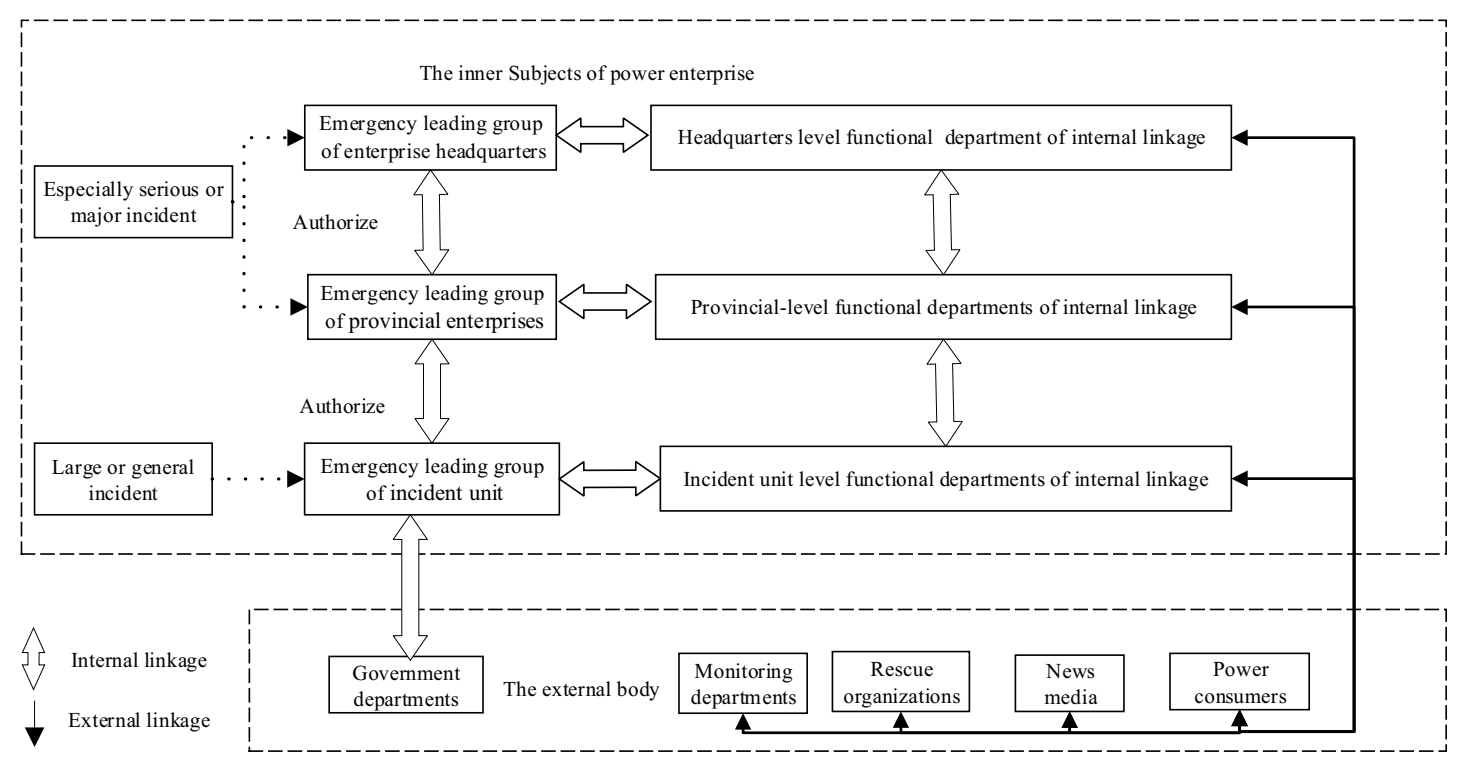

Figure 6. Comprehensive Emergency Linkage Mode

The mode has been applied in the State Grid Corporation of China. The corporation headquarters has established Emergency Linkage mechanism with 27 provincial companies in accordance with Emergency Linkage mode. Each provincial company has signed Emergency Linkage agreements with related units, according to themself characteristics. The State Grid Corporation of China organized 656 Emergency Linkage exercises with all levels of government departments. By applying Emergency Linkage mode, the various types of emergency resources of the State Grid Corporation of China have been scientific integration; external emergency power has been got the full benefits; and the emergency response capacity of corporation has been further enhanced.

\section{Conclusion}

On the basis of full study at domestic and foreign Emergency Linkage current state, we proposed the three elements of Emergency Linkage: Emergency Linkage subjects, Emergency Linkage content and Emergency Linkage level. They construct the basis for designing the modes of Emergency Linkage. We designed Power Enterprise Internal Emergency Linkage Mode (including Emergency Linkage Mode of Functional Department and Emergency Linkage Mode of Interior Units) and External Emergency Linkage Mode. The modes provide a scientific reference to build Power Enterprise Emergency Linkage mechanism, also help Power Enterprise further enhance emergency response capacity and improve the emergency management level.

\section{References}

1. Tian Shiming,Chen Xi,Zhu Chaoyang,et al.Theory of electric power emergency management and its technological countermeasures[J].Power System Technology,2007,31(24): 22-27. 
2. William L.Waugh, Jr Kathleen Tierney.Emergency Management Principles and Practice or Local Government[J]. the International City/ County Management Association,2007,58.

3. FU Shichun.Characteristics of Japanese Emergency Management System [J].Party \& Government Forum, 2009,4(4),60-62.

4. LI Geqin.On the Emergency and Security Management System in the United Kingdom [J].Journal of International Security Studies,2013,2(3),126-137.

5. GUO Yue. Characteristic of Disasters Management in Australia and Its Enlightenment [J].Journal of Chongqing Teachers College(Natural Science Edition),2005,4(12),59-63.

6. ZHU Xin-yan, LUO Fan.Study on Mechanism Optimization of Joint Emergency Response to Aviation Calamities in China [J].China Safety Science Journal,2007,17(6),9-15.

7. Liu Leyi.On Linkage of Emergency during Metro Operation [J].Modern Urban Transit,2007, 4(8),51-53.

8. ZHU Chaoyang,YU Zhen,LIU Chao.Research on Theory and Technical System for Power Emergency Management [J].Power System Technology,2011,35(2),178-182.

9. LIU Chao, ZHU Chao-yang,GONG Bo-tao,et al.Concepts,Indicators and Methods of Emergency Capability Assessment in City Power Grid Enterprises [J].East China Electric Power,2013,9(9),126-132. 